\title{
EDUKASI TANGGAP HIPERTENSI DI DESA LEMUKUTAN KECAMATAN SUNGAI RAYA KEPULAUAN KABUPATEN BENGKAYANG PROVINSI KALIMANTAN BARAT
}

\author{
Nurpratiwi ${ }^{1^{*}}$, Ali Akbar ${ }^{2}$, Mimi Amaludin ${ }^{3}$, Uti Rusdian Hidayat ${ }^{4}$, Fauzan \\ Alfikri $^{5}$, Debby Hatmalyakin ${ }^{6}$, Rifani Anggela ${ }^{7}$ \\ 1-7 STIKes Yarsi Pontianak \\ Email Korespondensi: nurpratiwi466@gmail.com
}

Disubmit: 15 November $2021 \quad$ Diterima: 23 Desember $2021 \quad$ Diterbitkan: 02 Januari 2022 DOI: https://doi.org/10.33024/jkpm.v1i1.5494

\begin{abstract}
ABSTRAK
Banyak dari penderita hipertensi yang tidak menyadari atau menganggap remeh akibat belum dirasakannya keluhan berarti meskipun tekanan darah sudah mencapai level berbahaya. Kondisi tersebut akan semakin berbahaya apabila masyarakat memiliki keterbatasan akses ke pelayanan kesehatan yang memadai seperti daerah-daerah pesisir pantai atau pulau-pulau kecil yang memerlukan transportasi air apabila ingin menuju ke pekayanan kesehatan yang memadai. Tujuan pengabdian kepada masyarakat untuk meningkatkan pengetahuan dan keterampilan masyarakat tentang tanggap hipertensi di Desa Lemukutan Kecamatan Sungai Raya Kepulauan. Metode palaksanaan pengabdian kepada masyarakat adalah penyuluhan tentang tanggap hipertensi dan pelatihan pengolahan mentimun serta prosedur rendam kaki air hangat dan jahe kepada masyarakat Desa Lemukutan Kecamatan Sungai Raya Kepulauan. Hasil pengabdian kepada masyarakat didapatkan data terjadi peningkatan pengetahuan masyarakat sebelum dan setelah penyuluhan kesehatan tentang tanggap hipertensi dengan hasil sebelum diberikan edukasi dan demonstrasi pengolahan penurun tekanan darah non farmakologis dan terapi terkait penurunan hipertensi sebagian besar peserta memiliki pengetahuan dan kemampuan pada kategori sedang yaitu $66,7 \%$, kategori rendah yaitu $30 \%$ dan kategori tinggi yaitu 3,33\%. Sedangkan setelah diberikan edukasi dan pengolahan penurun tekanan darah non farmakologis dan terapi terkait penurunan hipertensi diperoleh pengetahuan dan kemampuan pada kategori sedang yaitu $76,7 \%$ dan kategori tinggi yaitu $23,33 \%$.. Peningkatan pengatahuan masyarakat tentang hipertensi dan keterampilan dalam melakukan pengolahan mentimun serta prosedur rendam kaki air hangat jahe menjadi salah satu upaya pencegahan komplikasi hipertensi.
\end{abstract}

Kata Kunci: Edukasi, Pelatihan, Hipertensi 


\begin{abstract}
Many people with hypertension do not realize or underestimate the consequences of not having any significant complaints even though their blood pressure has reached a dangerous level. This condition will be even more dangerous if the community has limited access to adequate health services, such as coastal areas or small islands that require water transportation if they want to go to adequate health services. The purpose of community service is to increase community knowledge and skills about hypertension response in Lemukutan Village, Sungai Raya Islands District. The method of implementing community service is counseling about hypertension response and training on cucumber processing as well as foot soaking procedures in warm water and ginger to the people of Lemukutan Village, Sungai Raya Islands District. The results of community service showed that there was an increase in community knowledge before and after health counseling about hypertension response with the results before being given education and demonstration of nonpharmacological blood pressure lowering processing and therapy related to reducing hypertension, most of the participants had knowledge and abilities in the moderate category, namely $66.7 \%$, the low category is $30 \%$ and the high category is $3.33 \%$. Meanwhile, after being given education and processing nonpharmacological blood pressure lowering and therapy related to reducing hypertension, knowledge and abilities were obtained in the medium category, namely $76.7 \%$ and the high category, namely $23.33 \%$. Increasing public knowledge about hypertension and skills in processing cucumbers and The procedure of soaking feet in warm ginger water is an effort to prevent complications of hypertension.
\end{abstract}

Keywords: Education, Training, Hypertension

\title{
1. PENDAHULUAN
}

World Health Organization (WHO) melaporkan bahwa gangguan kardiovaskuler merupakan pembunuh nomor satu di dunia. Gangguan ini menyebabkan lebih dari 17 juta kematian yang mewakili 13\% dari kematian global (Who, 2015). Beberapa gangguan kardiovaskuler yang sering terjadi adalah penyakit jantung koroner, penyakit jantung bawaan dan hipertensi (Karo, 2016; Zainaro, Chrisanto, \& Perkasa, 2021).

Penyakit hipertensi merupakan penyakit yang timbul akibat adanya interaksi dari berbagai faktor risiko yang dimiliki seseorang (Oktaviarini, Hadisaputro, Suwando, \& Setyawan, 2019), hal ini yang menjadikan hipertensi sebagai salah satu penyakit yang memiliki angka morbiditas (kesakitan) dan mortalitasnya (kematian) yang tinggi. World Health Association (WHO) melaporkan bahwa kejadian Hipertensi diperkirakan mencapai 1 milyar di dunia, dan dua pertiga diantaranya berada di negara berkembang. Angka tersebut kian hari kian menghawatirkan yaitu sebanyak 972 juta (26\%) orang dewasa di dunia menderita hipertensi. Angka ini terus meningkat tajam, dan diprediksi pada tahun 2025 sekitar 29\% orang dewasa di seluruh dunia menderita hipertensi (Who, 2019) 
Prevalensi hipertensi di Indonesia terdiagnosis dengan usia > 18 tahun berjumlah 8,4 \% dari keseluruhan penduduk Indonesia dan Kalimantan Barat juga dengan usia $>18$ tahun dengan jumlah yang kurang lebih $8,4 \%$ dari jumlah penduduk kalbar. Dari 8,4\% penduduk Indonesia yang terdiagnosis hipertensi $27,8 \%$ profesi nelayan yang terdiagnosis hipertensi (Kementrian Kesehatan Republik, 2019) .

Lemukutan merupakan daerah pesisir yang mayoritas masyarakat berprofesi sebagai nelayan. Selain itu, masyarakat pesisir hal ini dikarenakan pulau lemukutan merupakan pulau yang di kelilingi lautan. Hasil studi pendahuluan melalui wawancara dengan menggunakan telpon dengan tokoh masyarakat yang bekerja di kantor desa menjelaskan total populasi penduduk pulau lemukutan berjumlah 1257 orang penduduk dengan pekerjaan utama sebagai nelayan. Menurut tokoh masyarakat tersebut mengungkapkan hipertensi merupakan diagnosis paling tingg terjadi dilemukutan. Salah satu yang paling berpengaruh masyarakat pulau lemukutan cenderung mengkonsumsi hanya hasil lautan bahkan hasil lautan yang dikeringkan seperti ikan asin yang jelas mengandung kadar garam yg tinggi yang merupakan salah satu faktor penyebab hipertensi. Menurut riset (Susantii, Sirega, \& Falefi, 2020) dengan hasil penelitian terdapat hubungan yang signifikan antara pola konsumsi makanan, status pendidikan dan umur terhadap kejadian hipertensi di wilayah pesisir ini dapat digunakan sebagai informasi, referensi dalam mengevaluasi cakupan program bagi petugas kesehatan, sehingga diharapkan untuk dapat meningkat upaya promosi kesehatan secara berkesinambungan khususnya kepada penderita hipertensi.

Sebagian besar guideline hipertensi merekomendasikan tatalaksana farmakologi pada pasien dengan TD 140/90 mmHg yang belum mencapai target TD yang diinginkan dengan modifikasi gaya hidup. Beberapa bukti menunjukkan bahwa pengobatan tekanan darah $>160 / 100 \mathrm{mmHg}$ dapat menurunkan kejadian stroke, infrak jantung, gagal jantung dan kematian 4-8 Terbukti bahwa terapi tekanan darah $>140 / 90 \mathrm{mmHg}$ khususnya pada pasien yang berisiko tinggi sangat bermanfaat. Hal yang berbeda didapat pada JNC8 yang menyatakan bahwa batas inisiasi terapi adalah 140/90 mmHg untuk dewasa umur 60 tahun. Faktor-faktor penentu keberhasilan terapi sebagaimana guidelines tersebut akan sulit direalisasikan apabila populasi memiliki keterbatasan akses ke layanan kesehatan yang memadai. hal ini lah yang menjadikan penyakit silent killer ini benar-benar akan mulai ditangani apabila penderita sudah merasakan keluhan yang tidak jarang sudah berada pada level hipertensi yang berbahaya. Berdasarkan laporan WHO, dari 50\% penderita hipertensi yang diketahui $25 \%$ diantaranya mendapat pengobatan, tetapi hanya $12,5 \%$ diantaranya diobati dengan baik (Who, 2012)

Konsep penanganan yang ideal juga harus mempertimbangkan aspek keamanan, mengingat pendekatan terapi farmakologi berpotensi menimbulkan masalah baru akibat efek samping dari penggunaan obat-obatan hipertensi dalam jangka waktu yang lama. Salah satu contoh efek samping yang umum terjadi adalah meningkatnya kadar gula dan kolesterol, kelelahan serta kehilangan energi. Tidak sedikit penderita yang harus mengkonsumsi obat lain untuk menghilangkan efek samping dari pengobatan hipertensinya. Satu-satunya cara yang dapat dilakukan untuk menghindari efek samping 
tersebut adalah dengan mengurangi terapi pengobatan farmakologis (Kharisna \& Dendy, 2012). Keterlambatan dalam memulai terapi serta pemilihan jenis obat hipertensi yang tidak sesuai dengan level dan target optimalisasi tekanan darah juga akan juga turut menjadi penyebab masalah baru bagi penderita hipertensi, oleh karena itu keputusan penanganan hipertensi pada level yang dapat ditoleransi akan sangat menentukan kualitas hidup penderita selanjutnya. Upaya memaksimalkan terapi nonfarmakologi seperti pengaturan pola hidup sehat atau merencanakan kebiasaan harian yang dapat membantu mencegah progresivitas penyakit hipertensi serta membantu kelompok rentan agar terhindar dari bahaya hipertensi. Beberapa hasil penelitian menunjukkan kemampuan terapi nonfarmakologi dalam mengembalikan target tekanan pada level tertentu.

Upaya yang dilakukan pasien hipertensi dengan terapi farmakologis ternyata masih menyisakan masalah yang lain bagi pasien hipertensi terutama pada aspek psikologis yaitu kecemasan. Munculnya keadaan cemas pada pasien hipertensi yang menjalani terapi farmakologis dapat terjadi karena kesalahan dalam menanggapi kondisi kesehatannya. (Berman, A, \& Frandsen, 2016) menyatakan bahwa ketika seseorang dalam kondisi sakit, mereka berperilaku dengan cara tertentu yang disebut sosiolog sebagai perilaku penyakit. Perilaku penyakit merupakan suatu mekanisme koping, melibatkan cara individu dalam menggambarkan, memantau, dan menafsirkan gejalagejalanya, mengambil tindakan perbaikan, dan menggunakan sistem perawatan kesehatan. Kondisi kesehatan yang buruk pada pasien hipertensi ini menjadi sebuah stressor bagi dirinya yang kemudian ditanggapi dengan cara sebagian adaftif dan sebagian maladaftif. Apabila respon maladaftif ini tidak ditangani dengan baik maka dapat menimbulkan masalah psikososial seperti kecemasan.

Salah satu terapi non-farmakologis yang dapat diberikan pada penderita hipertensi adalah terapi nutrisi yang dilakukan dengan manajemen diet hipertensi. Contohnya dengan pembatasan konsumsi garam, mempertahankan asupan kalium, kalsium, dan magnesium serta membatasi asupan kalori jika berat badan meningkat. Selain itu terapi yang sering digunakan masyarakat adalah buah mentimun yang sangat baik di konsumsi untuk penderita hipertensi. Mentimun dikatakan makanan yang sehat untuk pembuluh darah dan jantung, dimana makanan tersebut mengandung kalium yang bekerja sebagai melebarkan pembuluh darah sehingga tekanan darah menurun. Mentimun juga bersifat diuretik karena kandungan airnya yang tinggi sehingga membantu menurunkan tekanan darah dan dapat meningkatkan buang air kecil (Cerry, 2015) .Hal diatas berbanding lurus dengan riset yang dilakukan oleh (Barus, Ginting, \& Turnip, 2019) didapatkan hasil bahwa mentimun terbukti mempengaruhi beban kerja jantung, pompa kalium natrium, dan mendatangkan ketenangan yang pada akhirnya berpengaruh terhadap tekanan darah. Oleh karena itu, mengkonsumsi jus mentimun efektif untuk membantu menurunkan tekanan darah atau mengontrol tekanan darah agar tetap stabil pada pasien hipertensi.

Selain mengkonsumsi timun stimulasi fisik dengan rendam kaki air hangat jahe juga bisa menurunkan hipertensi. Menurut riset (Nurpratiwi, Hidayat, \& Putri, 2021) didapatkan hasil yaitu perasaan setelah melakukan rendam kaki 
air hangat jahe, manfaat rendam kaki air hangat jahe dalam menurunkan tekanan darah, waktu melakukan rendam kaki air hangat jahe, prosedur dalam melakukan rendam kaki air hangat jahe, jenis jahe yang digunakan, efek samping yang muncul setelah melakukan rendam kaki air hangat jahe.

Pemanfaatan terapi hipertensi secara alami sangat memungkinkan membantu penderita hipertensi untuk terhindar dari bahaya komplikasi. Kedisplinan dalam menjalankan terapi akan membuahkan hasil yang maksimal. Berdasarkan uraian data dan informasi di atas, maka penulis tertarik untuk melakukan penyuluhan pengabdian masyarakat untuk meningkatkan pengetahuan tentang penanganan hipertensi. Sehingga dapat mewujudkan derajat kesehatan masyarakat yang optimal serta hidup secara maksimal.

\section{MASALAH}

Gambaran permasalahan mitra adalah kurangnya pemahaman masyarakat dalam upaya penanganan hipertensi yang ditunjukkan masih terdapat masyarakat yang tidak patuh terhadap makanan-makanan yang dapat meningkatkan tekanan darah. Selain itu masyarakat juga masih tergantung hanya dengan obat-obat farmakologis untuk penanganan hipertensi. Solusi yang diupayakan adalah memberikan edukasi kepada masyarakat dan memberikan pelatihan kepada masyarakat dalam pengolahan buah mentimun dan rendam kaki dengan air jahe. Harapannya dengan memberikan edukasi kepada masyarakat menurunkan angka hipertensi dan mencegah terjadi komplikasi hipertensi. Jahe merupakan tumbuhan yang mudah ditemukan, jahe dapat menghalangi kalsium yang menyebabkan kontraksi jaringan otot polos pada organ dan dinding arteri sehingga dapat mengurangi kontraksi dan akan menghasilkan relaksasi otot maupun dinding arteri maka aliran darah menjadi lancer dan terjadilah penurunan tekanan darah.

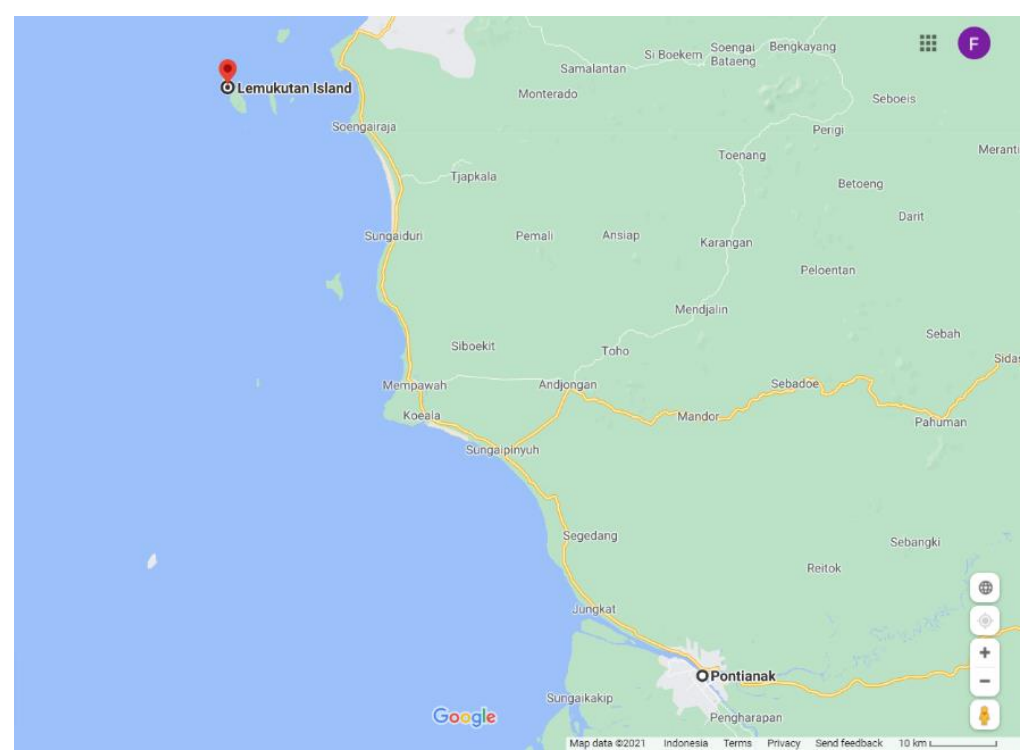

Gambar 1. Peta lokasi dan jarak Pontianak ke mitra kerjasama (pulau lemukutan) 


\section{METODE}

A. Metode pendekatan

Metode pendekatan dan prosedur kerja yang digunakan pada kegiatan pengabdian masyarakat ini adalah:

1. Edukasi. Edukasi diberikan untuk meningkatkan pengetahuan masyarakat tentang penanganan hipertensi. Edukasi dilakukan tatap muka dengan tetap sesuai protokol kesehatan.

2. Demonstrasi pengolahan mentimun serta prosedur rendam kaki air hangat jahe. Pelatihan dilakukan untuk meningkatkan pengetahuan tentang tatalaksana terapi.

B. Tahap Pelaksanaan Kegiatan

\section{Perizinan}

Team pelaksana pengabdian masyarakat mengajukan surat izin pelaksanaan kegiatan pengabdian masyarakat dengan desa mitra STIKes YARSI Pontianak yaitu Desa Lemukutan.

2. Koordinasi

Koordinasi dilakukan dengan kepala desa Lemukutan dan perangkat desa Lemukutan terkait tanggal pelaksanaan, waktu pelaksanaan dan selama proses pelaksanaan smpai kegiatan selesai.

3. Penyuluhan dan demonstrasi

Sebelum dilakukan penyuluhan dan demonstrasi peserta diminta untuk mengisi pre test. Setelah pre test dilakukan peserta diberikan penyuluhan tentang hipertensi dan demonstrasi trkait pembuatan rendaman air hangat jahe dan jus mentimun. Setelah dilakukan penyuluhan dilakukan kembali post test.

C. Evaluasi pelaksanaan dan berkelanjutan program

1. Evaluasi Pelaksanaan

Untuk mengevaluasi keterlaksanaan dan keberhasilan dari program yang direncanakan maka ditetapkanlah indikator sebagai acuan keberhasilan dari program sebagai berikut:

\begin{tabular}{|l|l|l|}
\hline No & \multicolumn{1}{|c|}{ Indikator } & \multicolumn{1}{c|}{ Mitra } \\
\hline 1 & $\begin{array}{l}\text { Meningkatnya pengetahuan } \\
\text { masyarakat tentang tanggap } \\
\text { hipertensi }\end{array}$ & $\begin{array}{l}\text { Masyarakat } \\
\text { pulau lemukutan }\end{array}$ \\
\hline 2 & $\begin{array}{l}\text { Meningkatnya pengetahuan } \\
\text { pengolahan penurun tekanan } \\
\text { darah non farmakologis dan } \\
\text { terapi terkait penurunan } \\
\text { hipertensi }\end{array}$ & $\begin{array}{l}\text { Masyarakat } \\
\text { pulau lemukutan }\end{array}$ \\
\hline
\end{tabular}


2. Evaluasi Program

Evaluasi kegiatan program ini dilakukan menggunakan kuesioner pretest dan posttest.

Tabel 2 Rancangan Evaluasi

\begin{tabular}{|c|c|c|}
\hline $\begin{array}{l}\text { Kriteria } \\
\text { Evaluasi }\end{array}$ & Indikator Pencapaian & Tolak Ukur \\
\hline $\begin{array}{l}\text { Pengetahuan } \\
\text { Peserta }\end{array}$ & $\begin{array}{l}\text { Hasil tahu peserta tentang materi } \\
\text { dengan parameter indikator: } \\
\text { - Pengetahuan masyarakat tentang } \\
\text { tanggap hipertensi } \\
\text { - Pengetahuan pengolahan penurun } \\
\text { tekanan darah non farmakologis dan } \\
\text { terapi terkait penurunan hipertensi }\end{array}$ & $\begin{array}{l}76-100 \%=\text { tingkat } \\
\text { pengetahuan tinggi } \\
=56-75 \%=\text { tingkat } \\
\text { pengetahuan sedang } \\
<56 \%=\text { tingkat } \\
\text { pengetahuan rendah }\end{array}$ \\
\hline
\end{tabular}

\section{HASIL DAN PEMBAHASAN}

Pelaksanaan pengabdian kepada masyarakat dilakukan pada masyarakat Desa Pulau Lemukutan dengan jumlah 30 peserta. Hasil pengabdian kepada masyarakat dijelaskan pada tabel 3.

Tabel 3. Distrbusi Frekuensi Pengetahuan Peserta Sebelum dan Setelah Edukasi tanggap hipertensi $(n=30)$

\begin{tabular}{cllll}
\hline \multirow{2}{*}{ Kategori } & \multicolumn{2}{c}{ Sebelum } & \multicolumn{2}{c}{ Setalah } \\
\cline { 2 - 5 } & $\mathrm{f}$ & $\%$ & $\mathrm{f}$ & $\%$ \\
\hline Rendah & 9 & 30 & 0 & 0 \\
\hline Sedang & 20 & 66,7 & 23 & 76,67 \\
\hline Tinggi & 1 & 3,33 & 7 & 23,33 \\
\hline
\end{tabular}

Tabel 1 menjelaskan bahwa sebelum diberikan edukasi dan demonstrasi pengolahan penurun tekanan darah non farmakologis dan terapi terkait penurunan hipertensi sebagian besar peserta memiliki pengetahuan dan kemampuan pada kategori sedang yaitu $66,7 \%$, kategori rendah yaitu $30 \%$ dan kategori tinggi yaitu 3,33\%. Sedangkan setelah diberikan edukasi dan pengolahan penurun tekanan darah non farmakologis dan terapi terkait penurunan hipertensi diperoleh pengetahuan dan kemampuan pada kategori sedang yaitu $76,7 \%$ dan kategori tinggi yaitu $23,33 \%$. Hasil pengabdian kepada masyarakat menjelaskan bahwa edukasi dan pengolahan penurun tekanan darah non farmakologis dan terapi terkait penurunan hipertensi dapat meningkatkan pengetahuan dan kemampuan masyarakat dalam pencegahan komplikasi dari hipertensi. Menurut (Khoirin \& Juliasih, 2020) Adanya peningkatan pengetahuan sesudah pemberian leaflet dan edukasi. Hal tersebut sejalan dengan penelitian (Adiatman \& Nursasi, 2020)edukasi efektif untuk pencegahan dan pengendalian hipertensi yang ditunjukkan dengan peningkatan pengetahuan, sikap, serta penurunan tekanan darah, namun tidak semua berpengaruh signifikan terhadap penurunan tekanan darah.

(Marquis \& Huston, 2010) mengungkapkan program edukasi dan pelatihanmerupakan metode yang baik untuk meningkatkan pengetahuan dan 
keterampilan seseorang untuk tujuan tertentu dalam melakukan tugas dan pekerjaannya. Pengetahuan merupakan bagian yang sangat penting untuk menentukan sikap dan perilaku seseorang. Menurut (Notoadmodjo, 2012) pengetahuan memiliki hubungan yang erat dengan perilaku seseorang. Pengetahuan yang baik dapat memicu perilaku yang baik.

Faktor pendukung kegiatan pengabdian kepada masyarakat Pihak mitra pemerinta Desa Pulau Lemukutan mendukung dan memfasilitasi selama proses pelaksanaan kegiatan, saat dilakukan kegiatan responden kooperatif dan interaktif, kegiatan edukasi dan pelatihan yang diikuti peserta sampai selesai. Sedangkan faktor pengahambat dalam kegiatan pengabdian kepada masyarakat adalah Akibat penyuluhan yang dilakukan pada senja hari maka berakibat pada keinginan responden untuk cepat pulang. Hal ini berdampak pada tidak fokusnya responden saat menjawab soal posttest.

Kegiatan pengabdian kepada masyarakat di Desa Lemukutan telah terdokumentasi. Berikut gambar pelaksanaan kegiatan pengabdian kepada masyarakat di Desa Lemukutan (gambar 1).
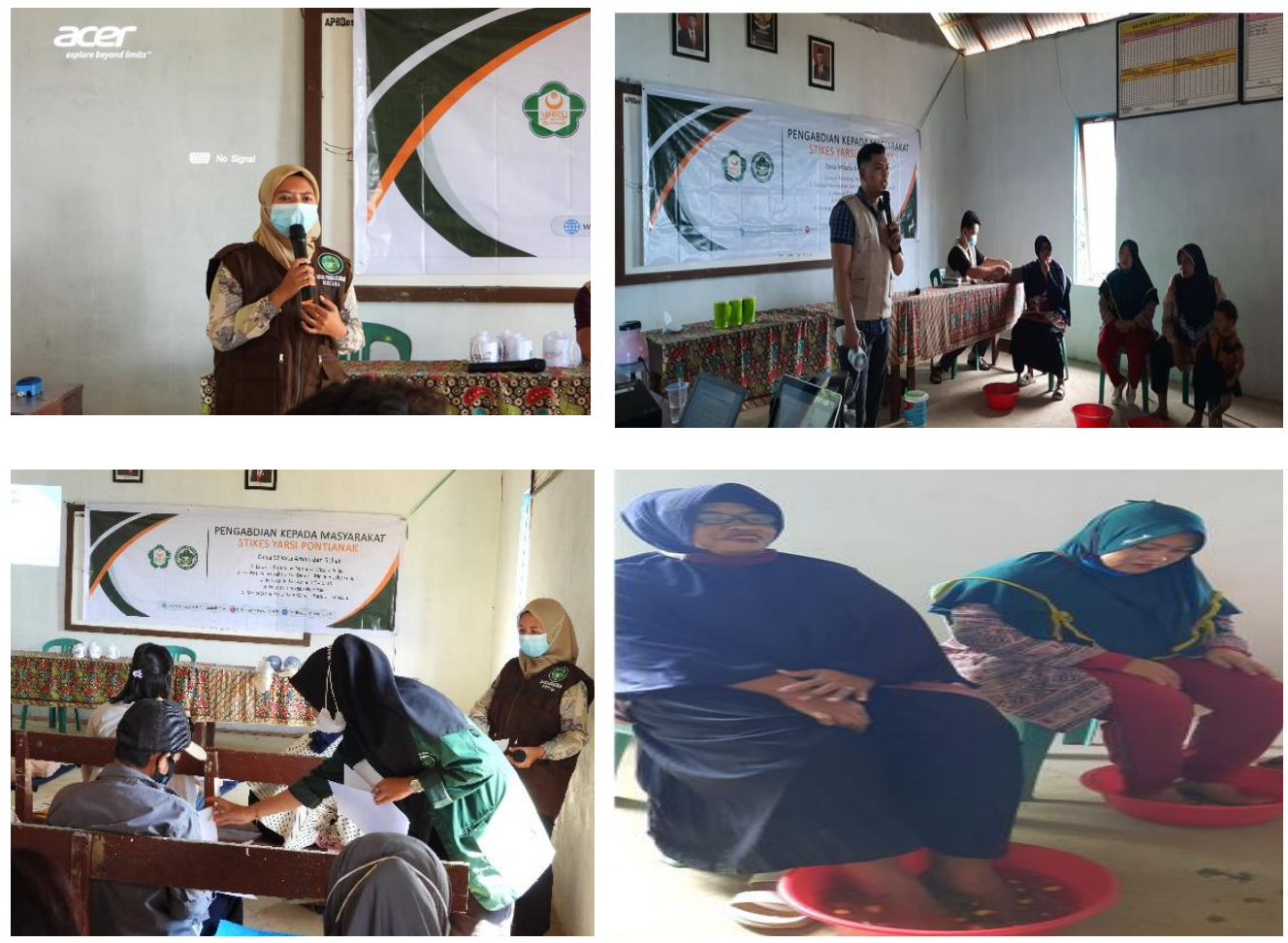

Gambar 1. Kegiatan Pengabdian Kepada Masyarakat di Desa Lemukutan

\section{KESIMPULAN}

Berdasarkan hasil pengabdian kepada masyarakat terdapat meningkatnya pengetahuan masyarakat tentang tanggap hipertensi dan meningkatnya pengetahuan pengolahan penurun tekanan darah non farmakologis dan terapi terkait penurunan hipertensi. 


\section{DAFTAR PUSTAKA}

Adiatman, \& Nursasi, A. Y. (2020). Efektifitas Edukasi dalam Pencegahan dan Pengendalian Hipertensi. Suara Forkikes, 11.

Barus, Ginting, \& Turnip. (2019). No Terapi jus Mentimun Menurunkan Tekanan Darah Pada Penderita HipertensiTitle. Jurnal Mutiara Ners, 2, 230-237.

Berman, A, S. S., \& Frandsen, G. (2016). Fundamentals of nursing: Concepts, process, \& practice. New York: Pearson.

Cerry. (2015). Pengaruh pemberian jus mentimun terhadaptekanan darah pada penderita hipertensidi desa tolombukan kec. Pasan Kab. Minahasa tenggara.

Karo, S. K. (2016). Cegah \& atasi penyakit jantung \& pembuluh darah. Jakarta: Praninta Aksara.

Kementrian Kesehatan Republik, I. (2019). Hipertensi Penyakit Paling Banyak Diidap Masyarakat.

Kharisna, \& Dendy. (2012). Efektifitas Konsumsi Jus Mentimun terhadap Penurunan Tekanan Darah pada Pasien Hipertensi.

Khoirin, \& Juliasih. (2020). Pengaruh Pemberian Leaflet Dan Edukasi Penyakit Hipertensi Terhadap Tingkat Pengetahuan.

Marquis, B. L., \& Huston, C. J. (2010). Kepemimpinan dan manajemen keperawatan : teori dan aplikasi. Jakarta: EGC.

Notoadmodjo, S. (2012). Metodologi penelitian kesehatan. Jakarta: Rineka Cipta.

Nurpratiwi, Hidayat, U. R., \& Putri, S. B. (2021). Rendam Kaki Air Hangat Jahe Dalam Menurunkan Tekanan Darah Pada Pasien Hipertensi. khatulistiwa Nursing Jurnal, 3(1). doi:https://doi.org/10.53399/knj.v3i1.55

Oktaviarini, E., Hadisaputro, S., Suwando, A., \& Setyawan, H. (2019). Faktor yang berisiko terhadap hipertensi pada pegawai di wilayah Perimeter Pelabuhan (Studi di Kantor Kesehatan Pelabuhan Kelas II Semarang). 4, 35-44.

Susantii, Sirega, \& Falefi. (2020). Determinan Kejadian Hipertensi Masyarakat Pesisir BerdasarkanKondisi Sosio Demografi dan Konsumsi Makan. 23379847.

Who. (2012). . Non comunnicable disease in Indonesia: A profile New Delhi.

Who. (2015). New initiative launched to tackle cardiovascular disease, the world's number one killer.

Who. (2019). Hypertension.

Zainaro, M. A., Chrisanto, E. Y., \& Perkasa, A. W. (2021). Asuhan keperawatan komprehensif dengan penerapan efektifitas foot massage dan progressive muscle relaxation terhadap penurunan tekanan darah pada penderita hipertensi. JOURNAL OF Public Health Concerns, 1(3), 151-161. 